\title{
Lung Stress and Strain during Mechanical Ventilation for Acute Respiratory Distress Syndrome
}

\author{
Davide Chiumello1, Eleonora Carlesso'2, Paolo Cadringher², Pietro Caironi 1,2, Franco Valenza ${ }^{1,2}$, Federico Polli2, \\ Federica Tallarini ${ }^{2}$, Paola Cozzi ${ }^{2}$, Massimo Cressoni ${ }^{2}$, Angelo Colombo ${ }^{1}$, John J. Marini ${ }^{3}$, and Luciano Gattinoni ${ }^{1,2}$ \\ ${ }^{1}$ Dipartimento di Anestesia, Rianimazione (Intensiva e Subintensiva) e Terapia del Dolore, Fondazione IRCCS-“'Ospedale Maggiore Policlinico \\ Mangiagalli Regina Elena" di Milano, Milan, Italy; ${ }^{2}$ Istituto di Anestesiologia e Rianimazione, Università degli Studi di Milano, Milan, Italy; and \\ ${ }^{3}$ Pulmonary and Critical Care, University of Minnesota and Regions Hospital, St. Paul, Minnesota
}

\begin{abstract}
Rationale: Lung injury caused by a ventilator results from nonphysiologic lung stress (transpulmonary pressure) and strain (inflated volume to functional residual capacity ratio).

Objectives: To determine whether plateau pressure and tidal volume are adequate surrogates for stress and strain, and to quantify the stress to strain relationship in patients and control subjects.

Methods: Nineteen postsurgical healthy patients (group 1), 11 patients with medical diseases (group 2), 26 patients with acute lung injury (group 3), and 24 patients with acute respiratory distress syndrome (group 4) underwent a positive end-expiratory pressure (PEEP) trial (5 and $15 \mathrm{~cm} \mathrm{H}_{2} \mathrm{O}$ ) with $6,8,10$, and $12 \mathrm{ml} / \mathrm{kg}$ tidal volume.

Measurements and Main Results: Plateau airway pressure, lung and chest wall elastances, and lung stress and strain significantly increased from groups 1 to 4 and with increasing PEEP and tidal volume. Within each group, a given applied airway pressure produced largely variable stress due to the variability of the lung elastance to respiratory system elastance ratio (range, 0.33-0.95). Analogously, for the same applied tidal volume, the strain variability within subgroups was remarkable, due to the functional residual capacity variability. Therefore, low or high tidal volume, such as 6 and $12 \mathrm{ml} / \mathrm{kg}$, respectively, could produce similar stress and strain in a remarkable fraction of patients in each subgroup. In contrast, the stress to strain ratio-that is, specific lung elastance-was similar throughout the subgroups $(13.4 \pm 3.4,12.6 \pm 3.0,14.4 \pm 3.6$, and $13.5 \pm 4.1 \mathrm{~cm} \mathrm{H}_{2} \mathrm{O}$ for groups 1 through 4 , respectively; $P=0.58$ ) and did not change with PEEP and tidal volume.

Conclusions: Plateau pressure and tidal volume are inadequate surrogates for lung stress and strain.

Clinical trial registered with www.clinicaltrials.gov (NCT 00143468).
\end{abstract}

Keywords: acute respiratory distress syndrome; acute lung injury; stress, mechanical; strain; ventilator-induced lung injury

Injury due to mechanical ventilation has been attributed to excessive pressure (barotrauma [1, 2]) or volume (volutrauma [3]) applied to the lung parenchyma, to shear stresses occurring at the interface of open and closed lung regions (atelectrauma $[4,5]$ ), and to cellular inflammatory response (biotrauma [6]). In the lung, the force-bearing structure is a skeleton composed of a fibrous network (elastin and collagen), embedded in the extracellular matrix. One fiber system originates from the hilum, the other from the lung periphery (visceral pleura), and the two systems are connected at the alveolar level (7). The

(Received in original form October 29, 2007; accepted in final form April 21, 2008) Supported by departmental funding only.

Correspondence and requests for reprints should be addressed to Prof. Luciano Gattinoni, M.D., F.R.C.P., Istituto di Anestesiologia e Rianimazione, Fondazione IRCCS-"Ospedale Maggiore Policlinico, Mangiagalli, Regina Elena" di Milano, Via Francesco Sforza 35, 20122 Milan, Italy. E-mail: gattinon@policlinico.mi.it

This article has an online supplement, which is accessible from this issue's table of contents at www.atsjournals.org

Am J Respir Crit Care Med Vol 178. pp 346-355, 2008

Originally Published in Press as DOI: 10.1164/rccm.200710-15890C on May 1, 2008

Internet address: www.atsjournals.org

\section{AT A GLANCE COMMENTARY}

Scientific Knowledge on the Subject

Lung stress and strain are the primary determinants of ventilator-induced lung injury. Their surrogates are airway pressure and tidal volume normalized for ideal body weight (VT IBW). Prevention of ventilator-induced lung injury is primarily based on recognizing the "harmful" threshold for these surrogates $\left(30 \mathrm{~cm} \mathrm{H}_{2} \mathrm{O}\right.$ airway plateau pressure and $6 \mathrm{ml} / \mathrm{kg}$ VT IBW).

What This Study Adds to the Field

In this study, we demonstrate that VT IBW and airway plateau pressure are inadequate surrogates for lung stress and strain.

elastin fibers are the determinants of elastic recoil, whereas the inextensible collagen fibers, folded when the lung is in its resting position, act as a "stop-length" when completely unfolded at total lung capacity $(8,9)$. Lung cells, anchored to the extracellular matrix, do not directly bear the force, but may activate the inflammatory cascade if subjected to excessive shape changes. When a force is applied to the fiber system, the upper limit of expansion is total lung capacity (fully unfolded collagen), after which stress may induce rupture. Before this limit, however, the nonphysiologic distension of lung cells may result in generalized lung inflammation (10-12).

In bioengineering parlance, stress and strain are mechanical phenomena properly referred to microstructures or to small areas of a body. "Stress" is defined as the internal distribution of the counterforce per unit of area that balances and reacts to an external load. The associated deformation of the structure is called "strain," which is defined as the change in size or shape referred to the initial status. Stress and strain are linked by the following formula (13):

$$
\text { stress }=k \times \text { strain }
$$

We reasoned that the clinical equivalent of stress is transpulmonary pressure (airway pressure minus pleural pressure) and the clinical equivalent of strain is the ratio of volume change $(\Delta \mathrm{V})$ to the functional residual capacity (FRC), which is the resting lung volume (14). We used FRC as a reference point, because at this volume the fibers of the lung skeleton are in their natural resting position, at atmospheric airway pressure, and the respiratory muscles, which are the "engine" of the strain, are inactive and relaxed. Accordingly, within the range of pressures and volumes for which the stress and strain relationship is linear, we get the following: 
TABLE 1. ADMISSION DIAGNOSIS OF THE STUDY POPULATION

\begin{tabular}{|c|c|c|c|}
\hline $\begin{array}{l}\text { Surgical Control } \\
\text { Subjects }(n=19)\end{array}$ & $\begin{array}{l}\text { Medical Control } \\
\text { Subjects }(n=11)\end{array}$ & $\begin{array}{l}\text { ALI Patients } \\
\quad(n=26)\end{array}$ & $\begin{array}{l}\text { ARDS Patients } \\
\quad(n=24)\end{array}$ \\
\hline \multirow{2}{*}{$\begin{array}{l}\text { Endocrine surgery } \\
\text { (nonabdominal) } \\
4 \text { patients }\end{array}$} & Head trauma & Pneumonia & Pneumonia \\
\hline & 2 patients & 4 patients & 9 patients \\
\hline Intracranial tumor & $\begin{array}{l}\text { Thrombotic } \\
\text { thrombocytopenic } \\
\text { purpura in SLE }\end{array}$ & Sepsis & Sepsis \\
\hline 14 patients & 1 patient & 13 patients & 9 patients \\
\hline \multirow[t]{6}{*}{$\begin{array}{l}\text { Kidney transplantation } \\
1 \text { patient }\end{array}$} & $\begin{array}{l}\text { Hemolytic syndrome } \\
1 \text { patient }\end{array}$ & $\begin{array}{l}\text { Aspiration } \\
3 \text { patients }\end{array}$ & $\begin{array}{l}\text { Aspiration } \\
2 \text { patients }\end{array}$ \\
\hline & $\begin{array}{l}\text { Metabolic-toxic coma } \\
1 \text { patient }\end{array}$ & $\begin{array}{l}\text { Trauma } \\
\text { No patients }\end{array}$ & $\begin{array}{l}\text { Trauma } \\
1 \text { patient }\end{array}$ \\
\hline & $\begin{array}{l}\text { Previous myocardial } \\
\text { infarction }\end{array}$ & Others* & Others* \\
\hline & 1 patient & 6 patients & 3 patients \\
\hline & $\begin{array}{l}\text { Drug intoxication } \\
2 \text { patients }\end{array}$ & & \\
\hline & $\begin{array}{l}\text { Postanoxic coma } \\
3 \text { patients }\end{array}$ & & \\
\hline
\end{tabular}

Definition of abbreviations: ALI = acute lung injury; ARDS = acute respiratory distress syndrome; SLE = systemic lupus erythematosus.

* Other causes of ALI included tetanus, liver transplantation, multiple transfusions, and recent surgery.

$$
\Delta \mathrm{P}_{\mathrm{L}}(\text { stress })=\mathrm{E}_{\mathrm{Lspec}}(\text { specific lung elastance }) \times \frac{\Delta \mathrm{V}}{\text { FRC }}(\text { strain })
$$

FRC must not be confused with end-expiratory lung volume measured with positive end-expiratory pressure (PEEP); in this case, the volume due to PEEP is part of $\Delta \mathrm{V}$ and must be added to the numerator and not to the denominator. This equation shows that the proportionality constant between stress and strain, called specific lung elastance, is the transpulmonary pressure at which FRC doubles. This parameter reflects the intrinsic elasticity of the lung parenchyma open to gases.

Because the determinants of ventilator-induced lung injury (VILI), stress and strain, are not measured in clinical practice, we sought to determine the extent to which they can be described by their clinical surrogates, plateau airway pressure and tidal volume, referenced to ideal body weight ( $\mathrm{V}_{\mathrm{T}} \mathrm{IBW}$ ). Therefore, in this article we measured the global average endtidal stress and defined the stress to strain relationship (specific lung elastance) in patients with acute lung injury/acute respiratory distress syndrome (ALI/ARDS) and control subjects. If lung stress and strain were not predictable from plateau airway pressure and $\mathrm{V}_{\mathrm{T}}$ IBW, their measurement would ideally allow physicians to tailor a safer mechanical ventilation in the individual patient in question.

\section{METHODS}

For more information on methods used, see the online supplement.

The study (March 2005 to May 2007) was approved by the institutional review board of the Fondazione IRCCS—-"Ospedale Maggiore Policlinico Mangiagalli Regina Elena" di Milano. Written, informed consent was obtained before surgery in conscious subjects and delayed in incompetent patients until they had recovered from sedation (following Italian legal regulations). The study population (Table 1) consisted of control subjects and patients with ALI/ARDS, divided in four subgroups: control subjects, 19 patients studied after elective surgery (excluding thoracic and abdominal surgery; group 1) 11 intensive care unit patients with medical diseases (group 2); and patients with ALI/ARDS, 26 with ALI (group 3) and 24 with ARDS (group 4) (15).

\section{Study Design}

Patients and control subjects were studied while supine during anesthesia and paralysis. The computer-driven protocol sequence (Figure 1) started with the measurement of FRC and end-expiratory lung volume at $5 \mathrm{~cm} \mathrm{H}_{2} \mathrm{O}$ PEEP. Thereafter, the lungs, at FRC, were inflated by an air-filled super-syringe with a volume equal to FRC, for direct measurement of the specific lung elastance. After this maneuver, we

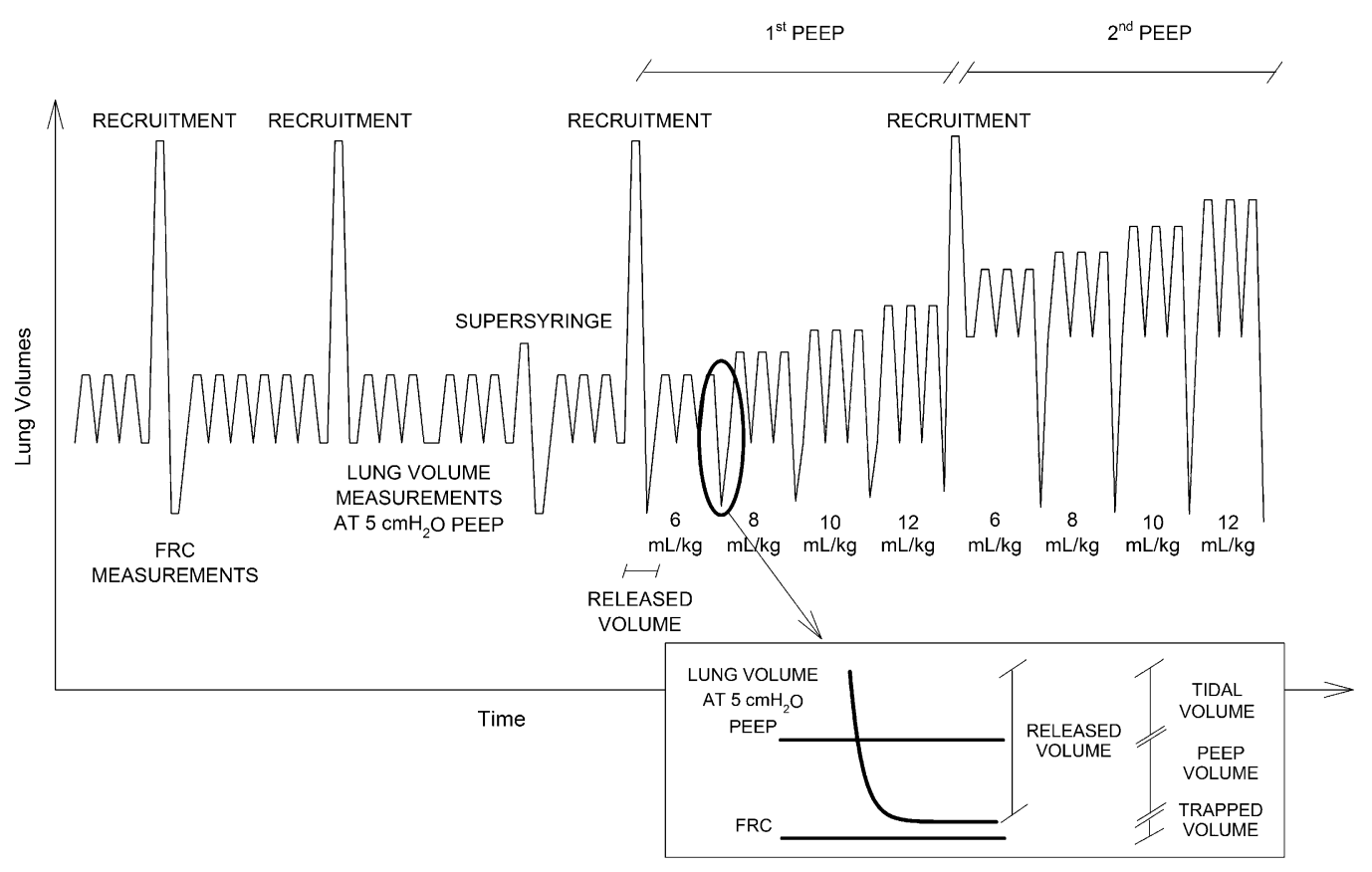

Figure 1. Schematic representation of the lung volume changes observed during the different steps of the experimental protocol. The timing of recruitment maneuvers, lung volume measurements (both at FRC and at $5 \mathrm{~cm} \mathrm{H}_{2} \mathrm{O}$ PEEP), measurements of specific lung elastance with supersyringe, and release maneuvers is also indicated. The inset shows the volumes necessary to compute the trapped-gas volume. As shown, inflated gas volume (above FRC) equals the sum of trapped-gas volume, PEEP volume, and tidal volume. Accordingly, trapped-gas volume was computed as end-expiratory lung volume minus FRC minus PEEP volume, where PEEP volume equals the released volume minus tidal volume. PEEP denotes positive end-expiratory pressure and $\mathrm{ml} / \mathrm{kg} \mathrm{V}_{\mathrm{T}}$ refers to VT IBW; 1 st and 2nd PEEP denote either 5 or $15 \mathrm{~cm} \mathrm{H} \mathrm{H}_{2} \mathrm{O}$ PEEP, according to the random sequence applied in each subject. 

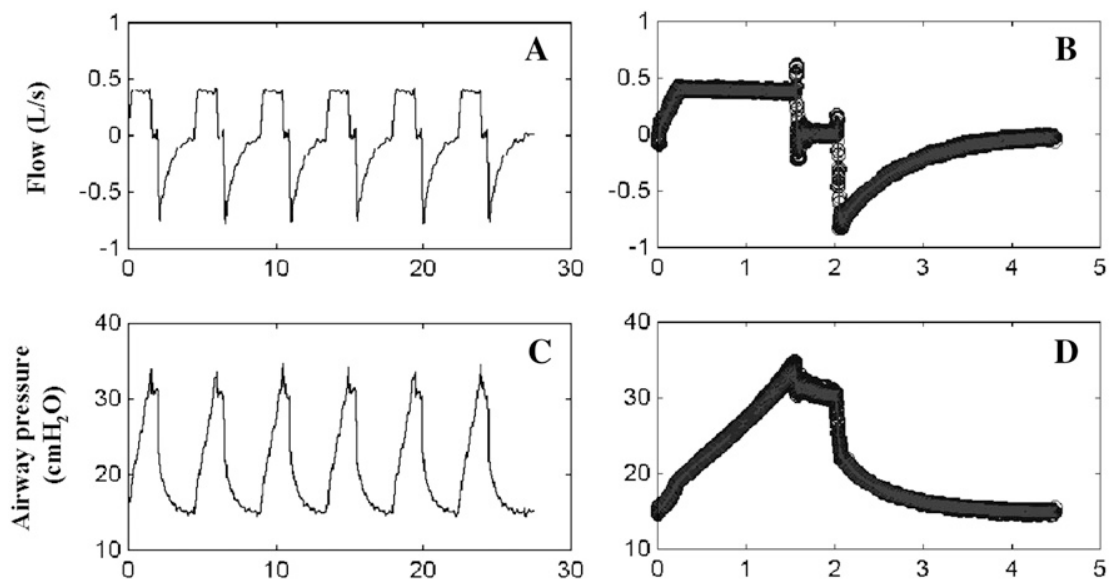

Figure 2. Experimental tracings. Six experimental tracings obtained in a single patient at $\mathrm{VT}_{\mathrm{T}} \mathrm{IBW} 6$ $\mathrm{ml} / \mathrm{kg}$ and $15 \mathrm{~cm} \mathrm{H}_{2} \mathrm{O}$ positive end-expiratory pressure (PEEP) $(A, C$, and $E)$. The right panels $(B, D$, and $F)$ show the average breath (see text for details); black dots represent the overlapped samples within the respiratory cycle, while gray lines represent mean \pm SD of the average breath.
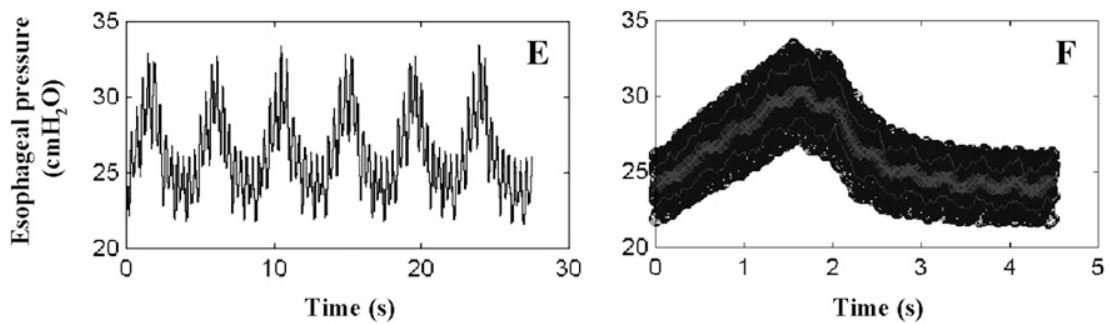

began the ventilatory trial consisting of 40 consecutive breaths with $\mathrm{VT}$ IBW of $6,8,10$, and $12 \mathrm{ml} / \mathrm{kg}$ sequentially applied at two different PEEP levels, 5 and $15 \mathrm{~cm} \mathrm{H}_{2} \mathrm{O}$, which were randomly set. After each VT IBW/PEEP combination, lungs were allowed to deflate from endinspiratory volume down to atmospheric pressure (released volume, $\Delta \mathrm{V})$.

\section{Measurements}

Flow, airway (Paw), and esophageal (Pes) pressures were recorded as previously described (16) and processed on a dedicated data acquisition system (Colligo; Elekton, Milan, Italy). The correct positioning of the esophageal catheter was checked by an inspiratory occlusion and we assumed that the variations of esophageal pressure measured the variations of pleural pressure. From the tracings, by resampling and an interpolation process (17), we obtained a single "average" breath for each patient and each ventilatory setting (Figure 2). Lung volumes were measured by helium dilution technique (18).

\section{Computations}

The delta transpulmonary pressure $\left(\Delta \mathrm{P}_{\mathrm{L}}\right)$ was computed as: $\Delta \mathrm{P}_{\mathrm{L}}=$ (Paw plateau - Pes plateau $)-\left(\right.$ atmospheric pressure $\left[0 \mathrm{~cm} \mathrm{H}_{2} \mathrm{O}\right]-\mathrm{Pes}$ at atmospheric pressure).

The average global strain was computed as: strain $=\Delta \mathrm{V} / \mathrm{FRC}$

The volume/pressure curves and the $\Delta$ volume/ $\Delta$ transpulmonary pressure curves were derived from the PEEP trial. The power equation

\section{TABLE 2. BASELINE CHARACTERISTICS}

\begin{tabular}{|c|c|c|c|c|c|}
\hline Age, yr & $56 \pm 14$ & $51 \pm 18$ & $64 \pm 15$ & $57 \pm 16$ & 0.11 \\
\hline Height, $\mathrm{cm}$ & $168 \pm 7$ & $169 \pm 8$ & $172 \pm 10$ & $172 \pm 9$ & 0.35 \\
\hline $\mathrm{V}_{T} \mathrm{IBW}, \mathrm{ml} / \mathrm{kg}$ & $9.9 \pm 2.0$ & $8.7 \pm 1.7$ & $9.0 \pm 2.2$ & $8.8 \pm 2.3$ & 0.29 \\
\hline Minute ventilation, $\mathrm{L} / \mathrm{min}$ & $6.3 \pm 1.0$ & $7.5 \pm 1.5$ & $7.3 \pm 1.5$ & $9.1 \pm 2.5^{\ddagger \ddagger}$ & $<0.0001$ \\
\hline Airway plateau pressure, $\mathrm{cm} \mathrm{H}_{2} \mathrm{O}$ & $17 \pm 2$ & $16 \pm 4$ & $22 \pm 5^{\dagger}$ & $24 \pm 5^{\dagger \S}$ & $<0.0001$ \\
\hline $\mathrm{Pa}_{\mathrm{O}_{2}}: \mathrm{Fl}_{\mathrm{O}_{2}}$ & $443 \pm 101$ & $314 \pm 77^{\dagger}$ & $249 \pm 30^{\dagger \S}$ & $126 \pm 43^{+\ddagger s}$ & $<0.0001$ \\
\hline $\mathrm{Fl}_{\mathrm{O}_{2}}$ & $43 \pm 6$ & $38 \pm 6$ & $44 \pm 6^{\S}$ & $49 \pm 12^{\dagger \ddagger \S}$ & 0.002 \\
\hline $\mathrm{Pa}_{\mathrm{CO}_{2}}, \mathrm{~mm} \mathrm{Hg}$ & $34 \pm 5$ & $34 \pm 5$ & $38 \pm 5$ & $39 \pm 7^{\dagger}$ & 0.006 \\
\hline Arterial $\mathrm{pH}$ & $7.46 \pm 0.04$ & $7.43 \pm 0.04$ & $7.41 \pm 0.06$ & $7.40 \pm 0.0^{\dagger}$ & 0.02 \\
\hline Days of ventilation before study\| & $0 \pm 0$ & $2 \pm 1^{\dagger}$ & $3 \pm 3^{\dagger}$ & $3 \pm 3^{\dagger}$ & $<0.0001$ \\
\hline
\end{tabular}

Definition of abbreviations: $\mathrm{ALI}=$ acute lung injury; ARDS = acute respiratory distress syndrome; IBW = ideal body weight; PEEP = positive-end expiratory pressure.

Values are means \pm SD or number of subjects (\%).

* $P$ values were obtained by one-way analysis of variance (ANOVA) or nonparametric one-way ANOVA and chi-square test analysis, as appropriate.

$+P<0.05$ for the comparison with surgical control group.

$¥ P<0.05$ for the comparison with patients with ALI.

$\S P<0.05$ for the comparison with medical control group.

"| Days of mechanical ventilation before the study were counted from the day of intubation (Day 0 ) to the beginning of the study. 
TABLE 3. BASELINE MECHANICAL CHARACTERISTICS

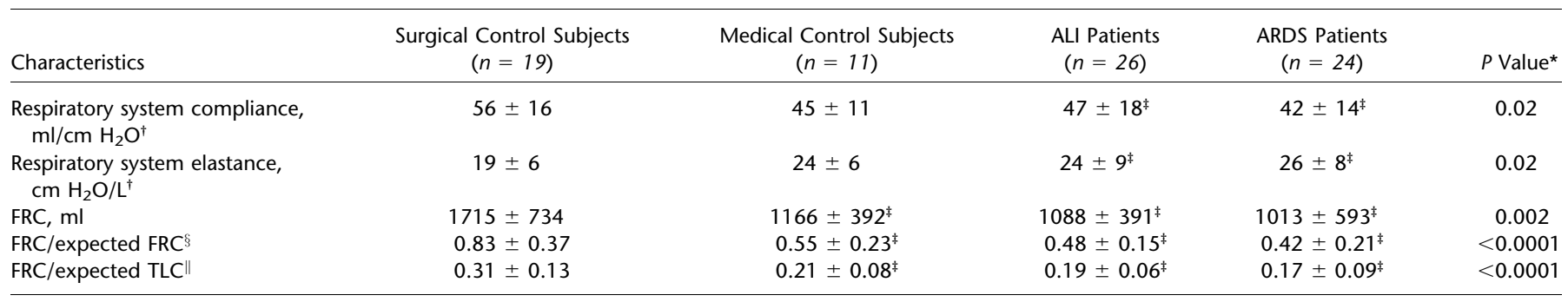

Definition of abbreviations: ALI = acute lung injury; ARDS = acute respiratory distress syndrome; TLC = total lung capacity.

Values are means \pm SD.

* $P$ values were obtained by one-way analysis of variance (ANOVA) or nonparametric one-way ANOVA as appropriate.

${ }^{\dagger}$ Respiratory system compliance was calculated as the ratio of the tidal volume to the difference between inspiratory airway plateau pressure and positive endexpiratory pressure.

$\ddagger P<0.05$ for the comparison with surgical control group.

$\S$ Expected FRC was calculated according to lbanez and colleagues (46).

" Expected TLC was calculated according to Stocks and colleagues (34).

$y=y_{0}+a \times x^{b}$ was fit to the data points and the dimensionless $b$ parameter was used to describe the shape of the curves (19) upward $(b>1.1)$, downward $(b<0.9)$, and linear $(0.9 \leqslant b \leqslant 1.1)$. The effect of inspiratory recruitment on strain computation are described in the online supplement. The specific lung elastance (Equation 2) was measured as $\Delta \mathrm{P}_{\mathrm{L}}$ recorded after inflating the lung (with a super- syringe) with a volume equal to FRC as well as the slope of the stress to strain relationship of each patient measured during the PEEP trial.

\section{Statistical Analysis}

Data are reported as mean $\pm \mathrm{SD}$, unless otherwise specified, and range, as appropriate. Statistical significance was defined as $P<0.05$.
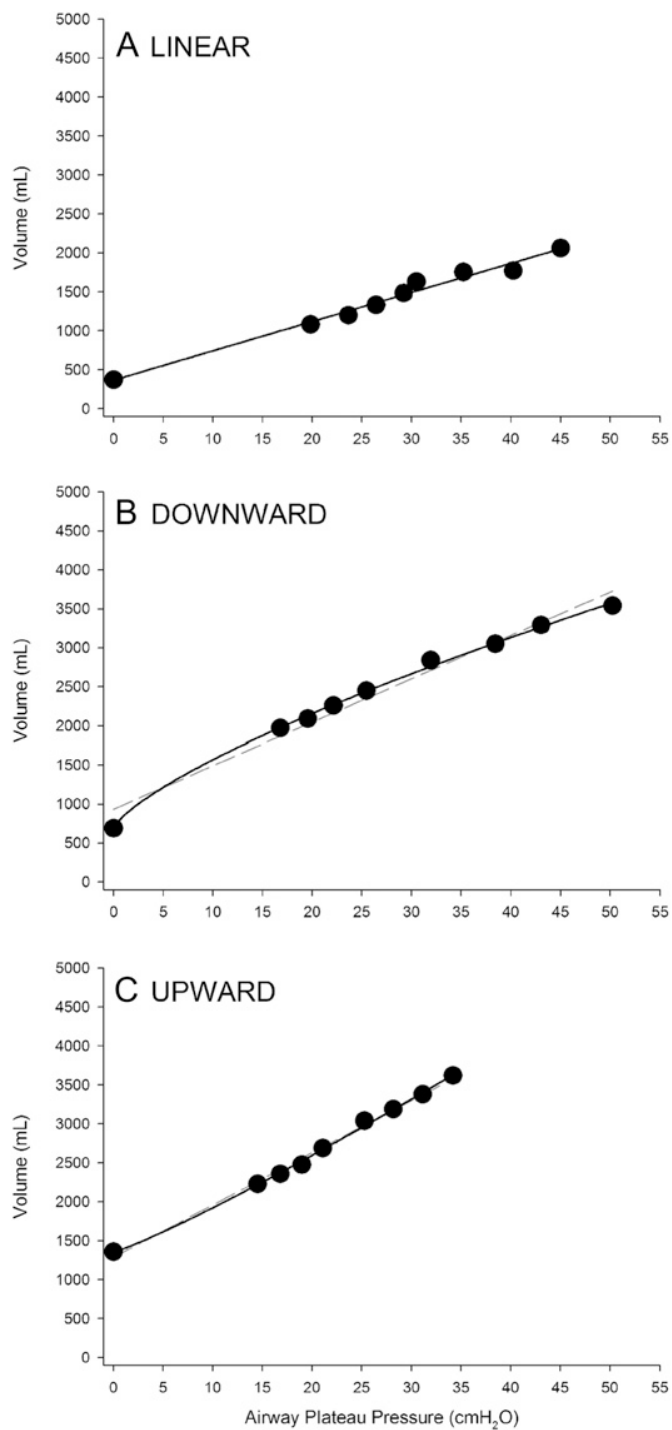
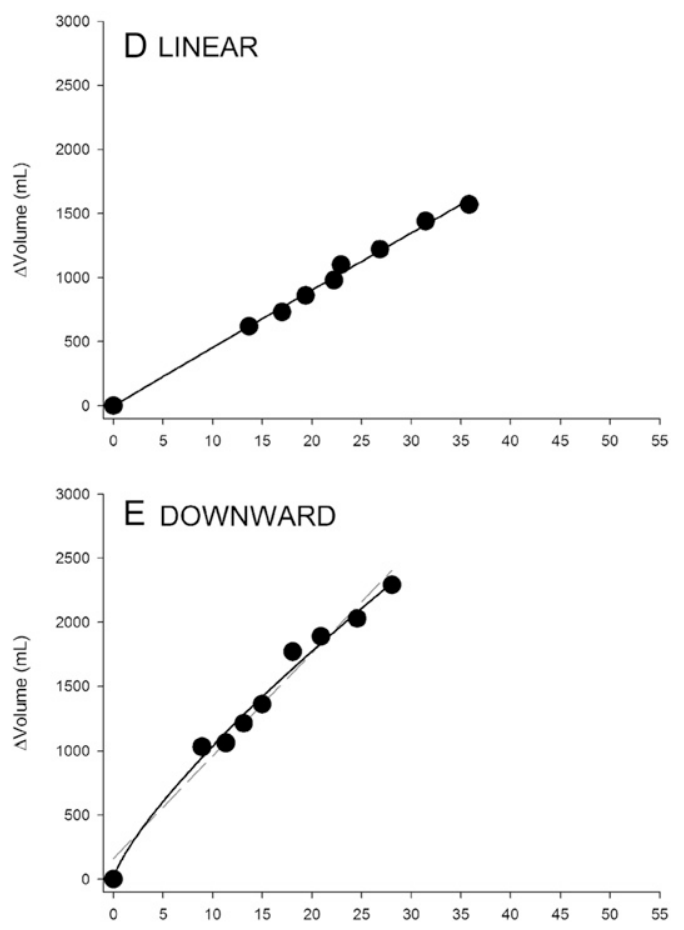

Figure 3. Volume/pressure curves. Representative volume/ pressure curves and $\Delta$ volume/ $\Delta$ transpulmonary pressure curves. $A, B$, and $C$ show volume/pressure curves of the respiratory system. $D, E$, and $F s$ show $\Delta$ volume/ $\Delta$ transpulmonary pressure curves of the lung. Black solid lines represent exponential fittings; gray dashed lines represent linear fittings.

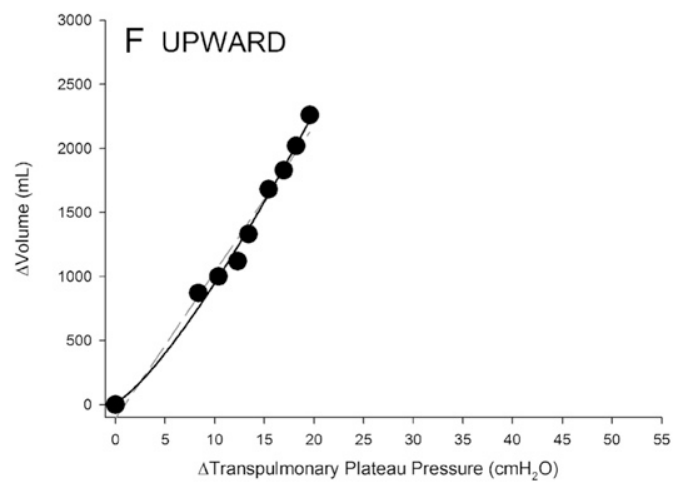




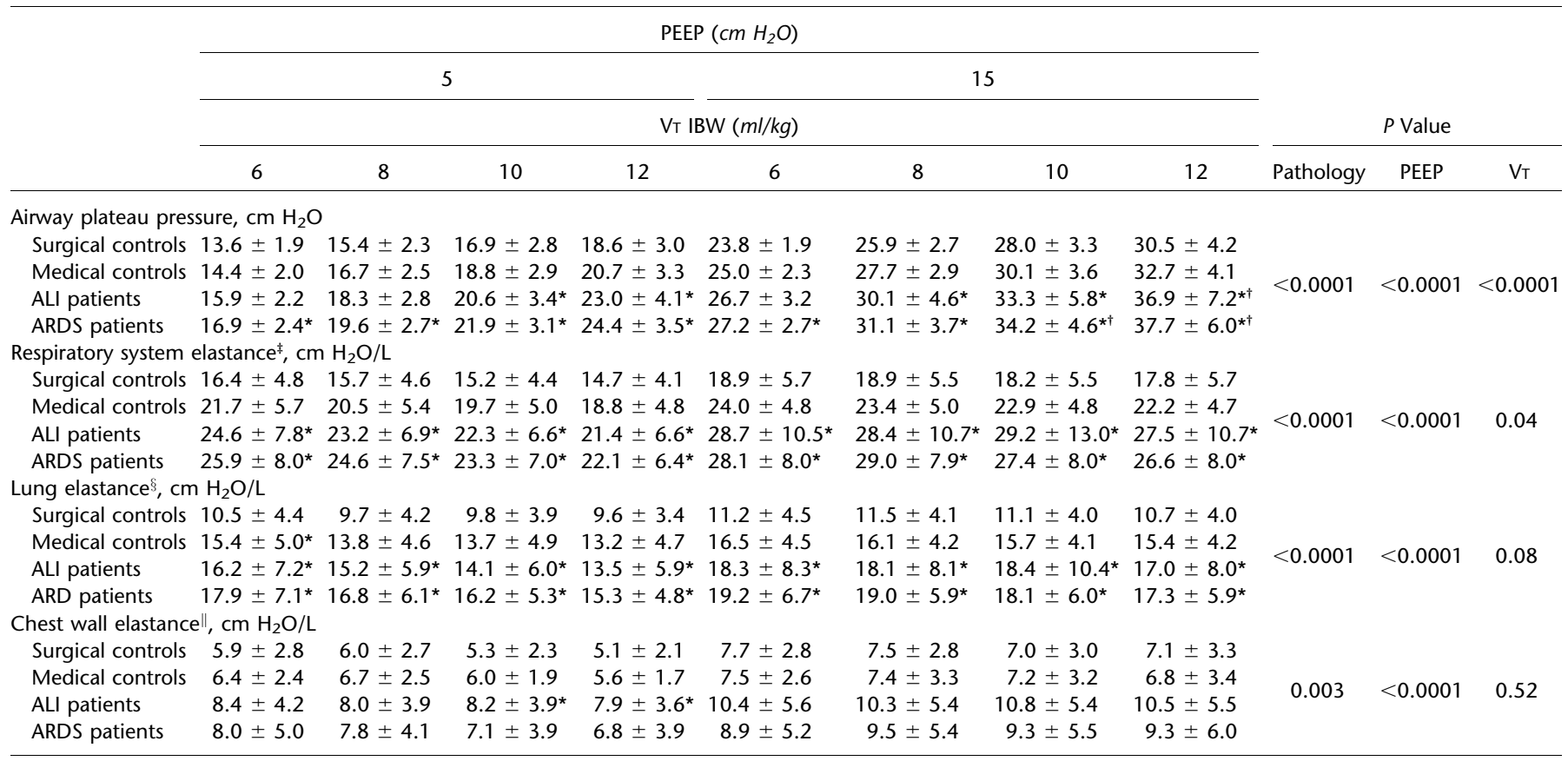

Definition of abbreviations: ALI = acute lung injury; ARDS = acute respiratory distress syndrome; PEEP = positive-end expiratory pressure; $\mathrm{VT}$ IBW = tidal volume per kg of ideal body weight.

Values are means \pm SD. Two statistical analyses are reported: a mixed-design three-way analysis of variance to test the effects of the presence of the disease, the level of PEEP, and the level of $\mathrm{VT}_{\mathrm{T}} \mathrm{IBW}$, as well as a post hoc Bonferroni's $t$ test analysis for the comparison between subgroups.

$* P<0.05$ for the comparison with surgical control subjects.

$+P<0.05$ for the comparison with medical control subjects.

${ }^{\ddagger}$ Respiratory system elastance was calculated as the ratio of the difference of the airway pressure at end inspiration and end expiration to the tidal volume. A logarithmic $\left(\log _{10}\right)$ transformation was used, as data were not normally distributed.

${ }^{\S}$ Lung elastance was calculated as the ratio of the difference of the transpulmonary pressure at end inspiration and end expiration to the tidal volume. A logarithmic $\left(\log _{10}\right)$ transformation was used, as data were not normally distributed.

"Chest wall elastance was calculated as the ratio of the difference of esophageal pressure at end inspiration and end expiration to the tidal volume. A logarithmic $\left(\log _{10}\right)$ transformation was used, as data were not normally distributed.

Comparison of baseline and physiologic variables was performed by one-way analysis of variance (ANOVA) for variables that were normally distributed, by nonparametric one-way ANOVA for variables that did not appear normally distributed on graphic inspection, and by chi-square test for qualitative variables. Power least squares fitting was used to describe volume/pressure curve shape. A Z-test was used to compare proportions of two groups. Mixed-design, three-way ANOVA was used to test the effects of the presence of the disease, the level of PEEP, and VT IBW. A logarithmic $\left(\log _{10}\right)$ transformation was used for data not normally distributed. Bonferroni's $t$ test was used to correct for multiple comparisons. Analysis was performed using SAS software, version 8.2 (SAS Institute, Cary, NC).

\section{RESULTS}

See the online supplement for more details on results.

\section{Study Population}

The baseline characteristics of the study population are presented in Table 2. Anthropometric characteristics were similar among the four subgroups. Patients with ARDS had worse gas exchange than patients in the other subgroups, and the differences in mechanical ventilator settings accounted for the different extent of lung impairment, increasing from group 1 to group 4. In Table 3 , we summarized the most relevant baseline variables of the respiratory system mechanics: from the healthiest control (the surgical subgroup) patients to the patients with full-blown ARDS, there is a progressive impairment of the elastance of the respiratory system $\left(\mathrm{E}_{\mathrm{TOT}}\right), \mathrm{FRC}$, and FRC normalized for expected FRC and expected total lung capacity.

\section{PEEP Trial}

Representative volume/pressure curves and $\Delta$ volume/ $\Delta$ transpulmonary pressure curves are shown in Figure 3. The volume/ pressure curves either of the total respiratory system or of the lung, when fitted with an exponential function, presented a downward concavity in $21 \%$ of patients with ALI/ARDS versus $13.3 \%$ of the control subjects $(P=0.31)$, were linear in 30 versus $20 \%(P=$ $0.23)$, and showed a slight upward concavity in 49 versus $67 \%(P=$ $0.04)$ in patients with ALI/ARDS versus control subjects, respectively. The linear fitting was also adequate; $75 \%$ of patients with ALI/ARDS and $78 \%$ of control subjects presented an $R^{2}$ greater than 0.95 (see the online supplement for details).

The summary of the respiratory system mechanics during the PEEP trial is reported in Table 4. As shown, the plateau airway pressure significantly increased, either with worsening lung conditions from group 1 to 4 , or with increasing PEEP or $V_{T}$ IBW. The respiratory system elastance increased significantly from group 1 to 4 and with increasing PEEP, whereas it slightly but significantly decreased with increasing $\mathrm{V}_{\mathrm{T}}$ IBW. The lung $\left(E_{L}\right)$ and chest wall elastance $\left(E_{C W}\right)$ significantly increased from group 1 to 4 and with increasing PEEP, whereas both $E_{L}$ and $\mathrm{E}_{\mathrm{CW}}$ did not significantly change at different $\mathrm{V}_{\mathrm{T}}$ IBW levels.

\section{Generation of Stress}

The relationship between plateau airway pressure and the corresponding $\Delta$ transpulmonary pressure (quantitatively equal to stress) is described by the following equation:

$$
\Delta \mathrm{P}_{\mathrm{L}}(\text { stress })=\Delta \mathrm{Paw} \times \mathrm{E}_{\mathrm{L}} /\left(\mathrm{E}_{\mathrm{L}}+\mathrm{E}_{\mathrm{CW}}\right)
$$


As shown, the $\Delta \mathrm{P}_{\mathrm{L}} / \Delta \mathrm{Paw}$ ratio equals the ratio of the lung elastance to the total elastance of the respiratory system $\left(\mathrm{E}_{\mathrm{L}}+\right.$ $\left.\mathrm{E}_{\mathrm{CW}}\right)$ and represents the pressure spent to distend the lung $\left(\Delta \mathrm{P}_{\mathrm{L}}\right)$ relative to the pressure spent to distend the whole respiratory system $(\Delta \mathrm{Paw})$. In Figure 4 , we report the $\Delta \mathrm{P}_{\mathrm{L}}$ as a function of $\triangle$ Paw recorded during the $\mathrm{PEEP}$ trial in the individual patients of the four subgroups at 5 and $15 \mathrm{~cm} \mathrm{H}_{2} \mathrm{O}$ PEEP and $\mathrm{VT}$ IBW of 6,8 , 10 , and $12 \mathrm{ml} / \mathrm{kg}$. The subgroups of patients with ALI/ARDS reached greater $\Delta \mathrm{Paw}$ pressure and $\Delta \mathrm{P}_{\mathrm{L}}$ than the two control subgroups (see also Tables 4 and 5). The slopes, $\Delta \mathrm{P}_{\mathrm{L}} / \Delta \mathrm{Paw}$ of the individual regressions (i.e., the individual $\mathrm{E}_{\mathrm{L}} /\left[\mathrm{E}_{\mathrm{L}}+\mathrm{E}_{\mathrm{CW}}\right]$ ), however, were not different in the four subgroups, and were, respectively, as follows: $0.69 \pm 0.15$ (range, $0.36-0.92$ ) in the surgical control subjects, $0.74 \pm 0.16$ (range, $0.37-0.95$ ) in the medical control subgroup, $0.64 \pm 0.15$ (range, 0.39-0.88) in the ALI subgroup, and $0.71 \pm 0.16$ (range, 0.33-0.92) in the ARDS subgroup $(P=0.26)$. In contrast, the $\mathrm{E}_{\mathrm{L}} /\left(\mathrm{E}_{\mathrm{L}}+\mathrm{E}_{\mathrm{CW}}\right)$ ratio was significantly greater in pulmonary versus extrapulmonary ARDS $(P=0.01)$ due to significant differences in lung and chest wall elastances (see the online supplement).

\section{Generation of Strain}

The average global strain significantly increased from group 1 to 4 , and with increasing VT IBW and PEEP (Table 5), and was significantly greater in patients with ALI/ARDS than in control subjects. In fact, the FRC decreased throughout the subgroups, from the healthiest surgical patients to the patients with ARDS (Table 3). Of note, however, within the same subgroup, for a given applied $\mathrm{V}_{\mathrm{T}}$ IBW and PEEP, and as already observed for lung stress (Figure 5), the lung strain variability was remarkable (Figure 6) due to FRC variability. We could not find any relationship between FRC, age, height, or body weight, either in patients with ALI/ARDS or in control subjects, who where anesthetized and paralyzed during the measurement.

\section{Stress/Strain Relationship}

As shown in Table 5, during the PEEP trial, the lung stress significantly increased from groups 1 to 4 and with increasing
PEEP and VT IBW. In contrast, the stress to strain ratio- that is, the specific lung elastance-was similar in the four subgroups and did not change throughout the different steps of the PEEP trial. This indicates a similar slope of stress to strain relationship as shown in Figure 7. In the four subgroups, we obtained the following values of the slope, which compared well with the values of specific lung elastance obtained by super-syringe: $13.3 \pm$ 4.9 versus $13.4 \pm 3.4 \mathrm{~cm} \mathrm{H}_{2} \mathrm{O}$ in the surgical control subjects $(P=$ $0.91), 12.8 \pm 5.4$ versus $12.6 \pm 3.0 \mathrm{~cm} \mathrm{H}_{2} \mathrm{O}$ in the medical control subjects $(P=0.83), 13.8 \pm 4.5$ versus $14.4 \pm 3.6 \mathrm{~cm} \mathrm{H}_{2} \mathrm{O}$ in patients with $\operatorname{ALI}(P=0.26)$, and $13.7 \pm 7.0$ versus $13.5 \pm 4.1 \mathrm{~cm} \mathrm{H}_{2} \mathrm{O}$ in patients with ARDS $(P=0.83)$. No association was found between specific lung elastance and the pathogenesis of ALI/ ARDS, or the duration of mechanical ventilation before the study.

\section{Lung Strain and Lung Recruitment}

Computing the strain as $\Delta \mathrm{V} / \mathrm{FRC}$ is correct only if the pulmonary units open at end inspiration are also open at end expiration. If new pulmonary units are recruited at end inspiration, the real strain will be lower, because the straining volume will be distributed on a greater number of pulmonary units (see model in the online supplement Figure E2). This model assumes that the recruited pulmonary units behave as the already-open units. According to this model (see online supplement for computation), we estimated the potential effect of lung recruitment (from 0 to $50 \%$ of $\mathrm{FRC}$ ) on decreasing lung strain in patients with ALI/ARDS. The results are presented in Figure 8. As shown, the effects of lung recruitment are remarkable at high $\Delta \mathrm{P}_{\mathrm{L}}$, and progressively decrease as $\Delta \mathrm{P}_{\mathrm{L}}$ decreases.

\section{DISCUSSION}

Our study population included a wide spectrum of mechanically ventilated patients, from healthy surgical patients to patients with the most severe forms of ARDS, throughout intermediate states, such as patients ventilated for medical systemic diseases without ALI/ARDS, and patients with ALI. In the whole population, we found that the plateau airway pressure and the tidal volume were not adequate surrogates for lung stress and
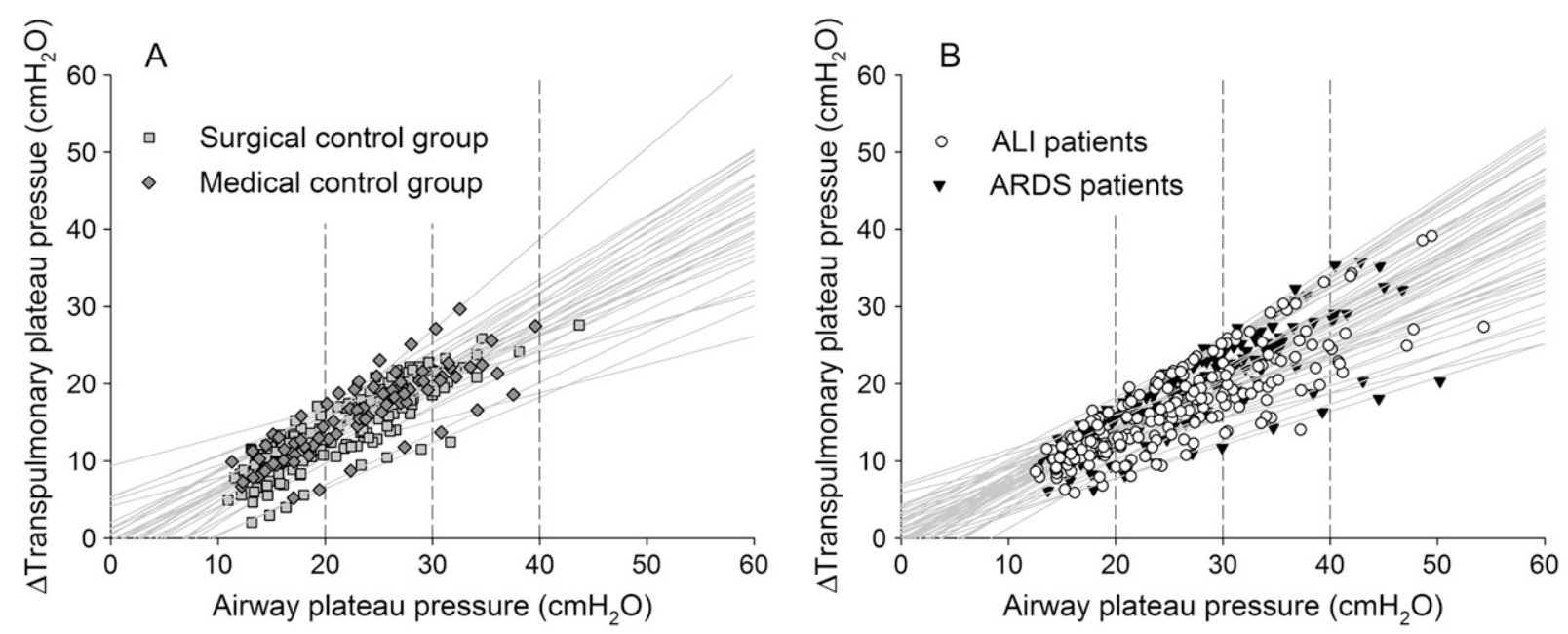

Figure 4. $\Delta$ Transpulmonary and airway pressure relationship in surgical control subjects, medical control subjects, patients with acute lung injury (ALI) and patients with acute respiratory distress syndrome (ARDS). (A) The $\Delta$ transpulmonary to airway pressure relationship in 30 control subjects, and $(B)$ the $\Delta$ transpulmonary to airway pressure relationship in 50 patients with ALI/ARDS. In both panels, gray solid lines represent the relationship observed in each individual subjects in the eight experimental conditions (i.e., four different $\mathrm{VT}_{T}[6,8,10,12 \mathrm{ml} / \mathrm{kg}$ idea body weight]), at two different positive end-expiratory pressure (PEEP) levels $\left(5\right.$ and $15 \mathrm{~cm} \mathrm{H}_{2} \mathrm{O}$ ). A linear function $\left(y=a x+y_{0}\right)$ was used. Vertical dashed lines at 20 , 30 , and $40 \mathrm{~cm} \mathrm{H} \mathrm{H}_{2} \mathrm{O}$ airway pressure were drawn to underline the large variability of the corresponding $\Delta$ transpulmonary pressure both in control subjects and patients. 
TABLE 5. LUNG STRESS, STRAIN AND SPECIFIC LUNG ELASTANCE DURING THE POSITIVE END-EXPIRATORY PRESSURE TRIAL

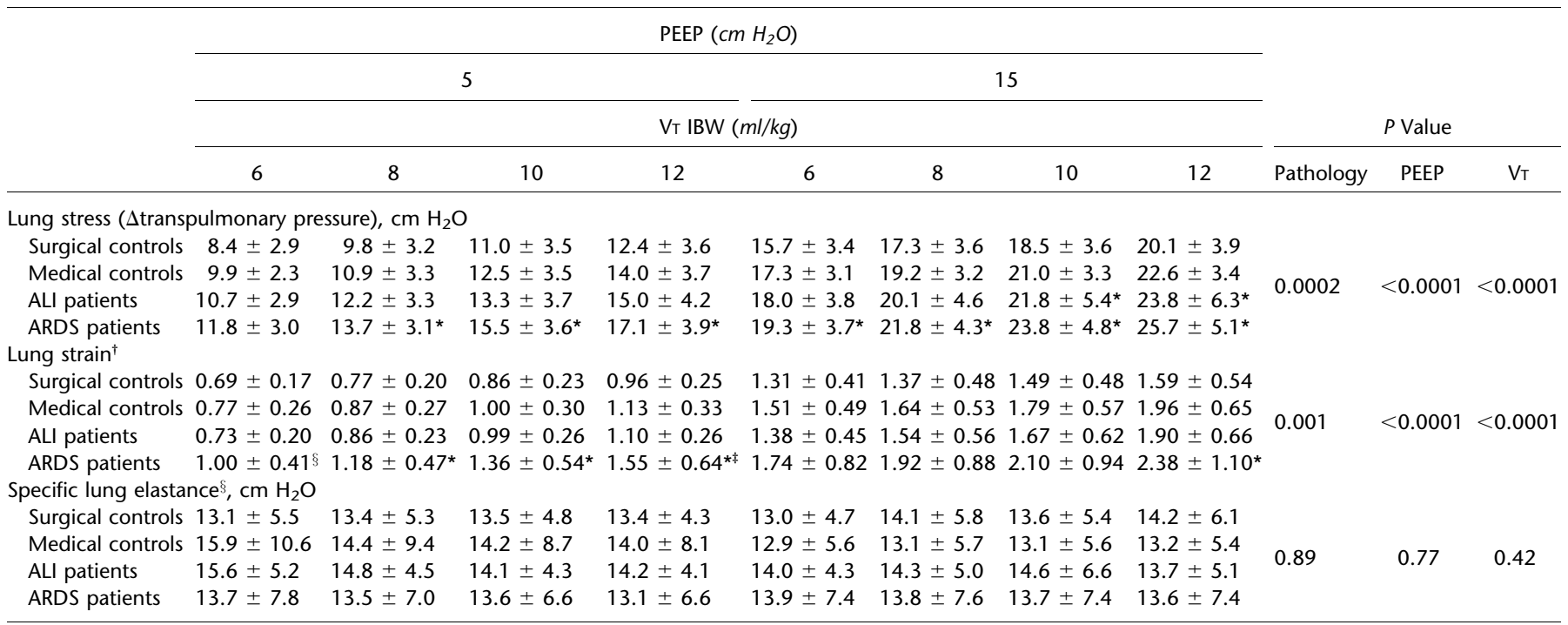

For definition of abbreviations, see Table 4

Values are means \pm SD. Two statistical analyses are reported: a mixed-design three-way analysis of variance to test the effects of the presence of the disease, the level of PEEP, and the level of $\mathrm{VT}_{\mathrm{T}}$, as well as a post hoc Bonferroni's $t$ test analysis for the comparison between subgroups.

* $P<0.05$ for the comparison with surgical control subjects.

${ }^{\dagger}$ Lung strain was calculated as the ratio of the end-inspiratory inflated volume to the FRC (for further details, see the online supplement). A logarithmic (log ${ }_{10}$ ) transformation was used, as data were not normally distributed.

$¥ P<0.05$ for the comparison with patients with ALI.

$\S$ Specific lung elastance was calculated as the ratio of $\Delta$ transpulmonary pressure to lung strain.

strain. Moreover, we found that the stress to strain relationship was the same in all the subgroups we studied, that it was linear, or nearly linear, in the ranges of pressures and volumes we explored, and that the specific lung elastance was similar in the subgroups and independent of ventilator setting.

Because most of our results and inferences are based on the accuracy of esophageal manometry, a highly controversial

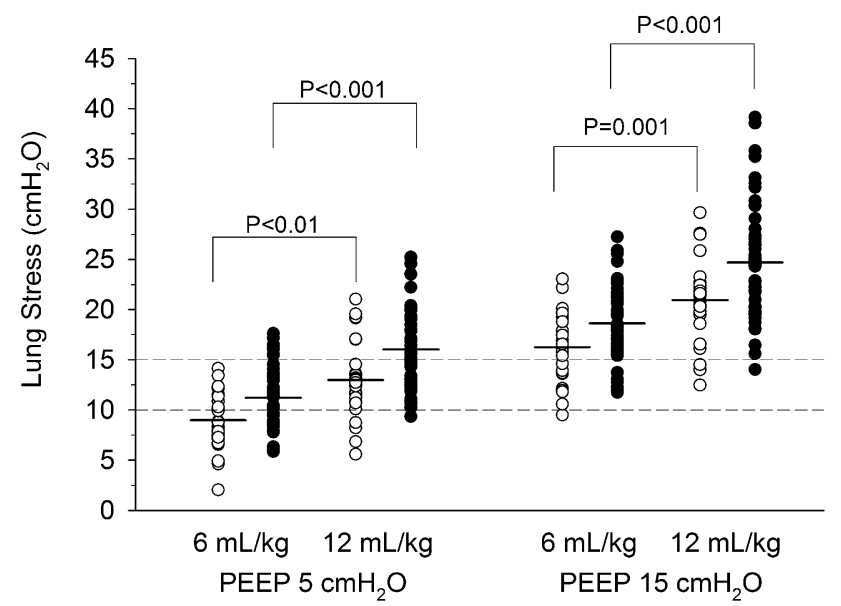

Figure 5. Lung stress at 6 and $12 \mathrm{ml} / \mathrm{kg} \mathrm{V}_{\mathrm{T}} \mathrm{IBW}$ in patients with acute lung injury (ALI) or acute respiratory distress syndrome (ARDS) and control subjects. For clarity, surgical and medical control subjects were grouped together as were the patients with ALI and ARDS (see the online supplement for further details). Individual values of lung stress detected in patients with ALI/ARDS (solid circles) and in control subjects (open circles) are reported, both at 6 and $12 \mathrm{ml} / \mathrm{kg} \mathrm{VT} \mathrm{IBW} \mathrm{with} \mathrm{positive}$ end-expiratory pressure (PEEP) of 5 and $15 \mathrm{~cm} \mathrm{H}_{2} \mathrm{O}$. Black solid lines represent mean values of each group. Dashed lines were drawn at lung stress of 10 and $15 \mathrm{~cm} \mathrm{H}_{2} \mathrm{O}$ to underline the overlap of lung stress at different $\mathrm{V}_{\mathrm{T}} \mathrm{IBW}$ and PEEP. measurement in critically ill patients $(20,21)$, a brief discussion on its value is appropriate. Many factors may alter the esophageal/pleural pressure relationship, such as the esophageal balloon elastance, the tone of the esophageal wall, as well as heart/lung weight and patient position (21). Moreover, the pleural pressure varies along the lung vertical axis as detected by esophageal manometry and inferred by the computed tomog-

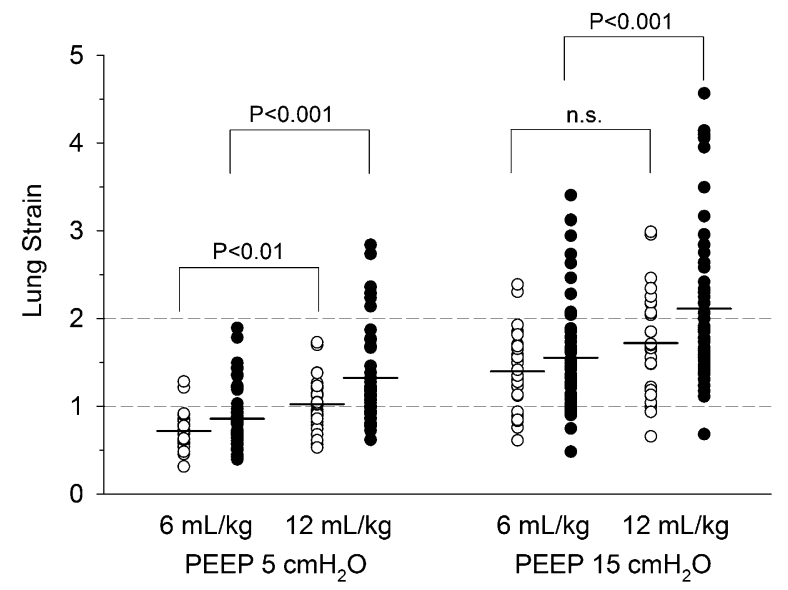

Figure 6. Lung strain at 6 and $12 \mathrm{ml} / \mathrm{kg} \mathrm{V}_{\mathrm{T}} \mathrm{IBW}$ in patients with acute lung injury (ALI) or acute respiratory distress syndrome (ARDS) and control subjects. For clarity, surgical and medical control subjects were grouped together as were the patients with ALI and ARDS (see the online supplement for further details). Individual values of lung strain detected in patients with ALI/ARDS (solid circles) and in control subjects (open circles) are reported, both at 6 and $12 \mathrm{ml} / \mathrm{kg} \mathrm{VT} \mathrm{IBW} \mathrm{with} \mathrm{positive}$ end-expiratory pressure (PEEP) of 5 and $15 \mathrm{~cm} \mathrm{H}_{2} \mathrm{O}$. Black solid lines represent mean values of each group. Dashed lines were drawn at lung strain of 1 and 2 to underline the overlap of lung strain at different $V_{T}$ IBW and PEEP. 


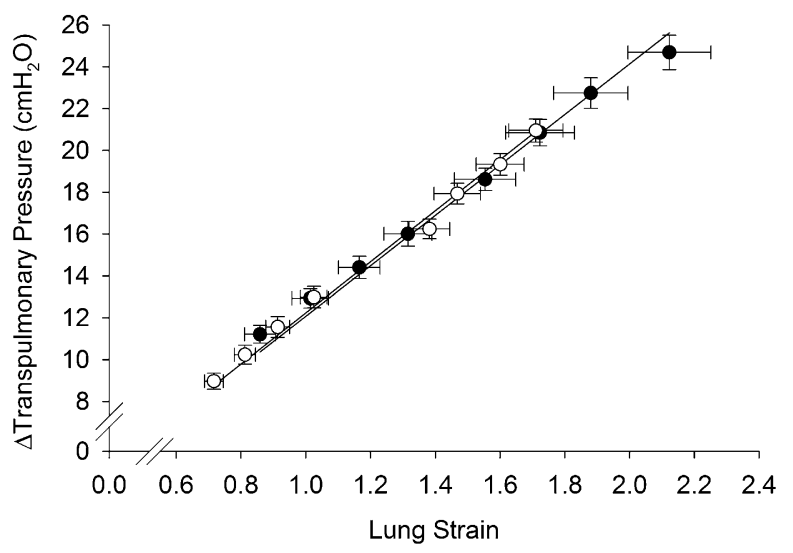

Figure 7. Lung stress to strain relationship in patients with acute lung injury (ALI) or acute respiratory distress syndrome (ARDS) and control subjects. For clarity, surgical and medical control subjects were grouped together as were the patients with ALI and ARDS (see the online supplement for further details). The relationships between mean values of $\Delta$ transpulmonary pressure (i.e., lung stress) and lung strain recorded for both patients with ALI/ARDS (solid circles) and control subjects (open circles) are reported. For clarity, data are shown as mean and standard error. The alignment of the average data points of patients with ALI/ARDS and healthy subjects emphasizes the similarity of the stress to strain relationships of the two populations.

raphy scan (22). We studied experimentally the esophageal/ pleural pressure relationship in supine, oleic acid-injured dogs (23). We found that esophageal pressure nearly equals the surface pleural pressure measured directly by wafers in the middle lung, is greater than the pleural pressure in the upper lung, and is lower than pleural pressure in the lower lung. The variations of pleural pressure, however, were similar to the variations of esophageal pressure at each lung level, as previously observed by other investigators (24-27). Indeed, the bulk of data suggests that the esophageal pressure variations, as used in this study, are the best available surrogate of pleural pressure variations. Of course, if the esophageal pressure variations are not coincident with pleural pressure variations, the error introduced in our stress estimate will be equal to the ratio of $\Delta$ (esophageal pressure) to $\Delta$ (average true pleural pressure).

\section{PEEP Trial and Stress/Strain Generation}

In most of the patients, during the PEEP trial, we obtained linear or nearly linear volume/pressure curves. Indeed, our derived variables, such as lung and chest wall elastance, the $E_{L} /$ $\left(E_{L}+E_{C W}\right)$ ratio, and the specific lung elastance, can be adequately described by a single value. Our results confirm that $\Delta \mathrm{P}_{\mathrm{L}}$ cannot be predicted from the airway pressure, as previously shown (28), due to the great variability of the ratio of lung elastance to the total respiratory system elastance $(14,29,30)$ (see Equation 3). In fact, the $E_{L} /\left(E_{L}+E_{C W}\right)$ ratio in the ALI/ARDS subgroups ranged from 0.33 to 0.92 and, surprisingly, from 0.36 to 0.95 in the subgroups of surgical and medical patients. This implies that, for a given applied airway pressure to the whole respiratory system (e.g., $30 \mathrm{~cm} \mathrm{H}_{2} \mathrm{O}$ ), the resulting $\Delta$ transpulmonary pressure may be as low as approximately $10 \mathrm{~cm} \mathrm{H}_{2} \mathrm{O}$ or as high as approximately $28 \mathrm{~cm} \mathrm{H}_{2} \mathrm{O}$ (see Figure 4). This range of $\mathrm{E}_{\mathrm{L}} /\left(\mathrm{E}_{\mathrm{L}}+\mathrm{E}_{\mathrm{CW}}\right)$ ratios may appear unrealistic, particularly in control subjects, in whom normal lung and chest wall elastances are expected. However, it must be considered that $E_{L} /\left(E_{L}+E_{C W}\right)$ is a ratio and each "normal value" has its own standard deviation and range. For example, in a normal patient, in whom

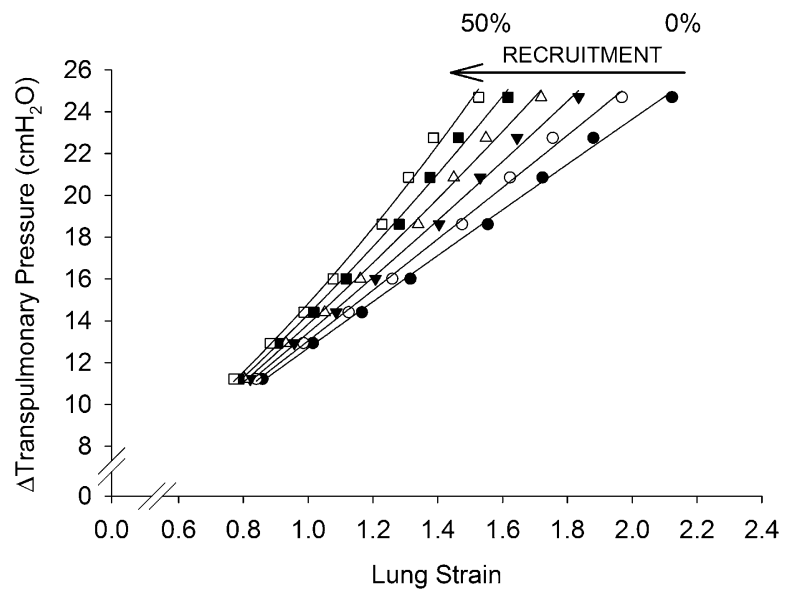

Figure 8. Lung stress to strain relationship as corrected for lung recruitment in patients with acute lung injury (ALI) or acute respiratory distress syndrome (ARDS). The relationship between lung stress (i.e., $\Delta$ transpulmonary pressure) and lung strain is reported after the adjustment of lung strain for different percentage of lung recruitment. Adjustment of lung strain for recruitment was computed as follows: the maximal lung recruitment (the recruitment occurring at the highest pressure) was first arbitrarily established as a fraction of FRC (from 0 to $50 \%$ ). Because the fractional recruitment is a function of the airway pressure applied, the fractional lung recruitment at each inspiratory airway pressure was then computed according to a sigmoid function derived from Crotti and colleagues (45) (computed tomography scanbased data), and the recruited gas volume was finally calculated. The adjusted strain was computed as the volume change divided by the sum of gas volume at FRC and the recruited gas volume. Solid circles denote values for a lung recruitment of $0 \%$ FRC, open circles denote values for a lung recruitment of $10 \%$ of $\mathrm{FRC}$, inverted solid triangles denote values for a lung recruitment of $20 \%$ of FRC, open triangles denote values for a lung recruitment of $30 \%$ of $F R C$, solid squares denote values for a lung recruitment of $40 \%$ of FRC, and open squares denote values for a lung recruitment of $50 \%$ of FRC.

the chest wall elastance is in its lowest normal value $(\sim 2 \mathrm{~cm}$ $\mathrm{H}_{2} \mathrm{O} / \mathrm{L}$ ) and in whom, during anesthesia and paralysis, the lung elastance rises to $20 \mathrm{~cm} \mathrm{H}_{2} \mathrm{O} / \mathrm{L}$ due to the lung collapse, the $\mathrm{E}_{\mathrm{L}} /$ $\left(E_{L}+E_{C W}\right)$ ratio will be $20 / 22=0.91$, which is only apparently an unrealistic value. In fact, the mechanical set described above will produce a plateau pressure of $11 \mathrm{~cm} \mathrm{H}_{2} \mathrm{O}$ with a tidal volume of $500 \mathrm{ml}$, which is a very common observation during normal anesthesia. On the other hand, a remarkably low $E_{L} /$ $\left(\mathrm{E}_{\mathrm{L}}+\mathrm{E}_{\mathrm{CW}}\right)$ ratio, such as 0.33 , may be observed in a patient with ALI from abdominal disease, with a respiratory system elastance of $24 \mathrm{~cm} \mathrm{H}_{2} \mathrm{O} / \mathrm{L}$ and an intraabdominal pressure of $30 \mathrm{~cm}$ $\mathrm{H}_{2} \mathrm{O}$. In this case, the chest wall elastance could rise up to $16 \mathrm{~cm}$ $\mathrm{H}_{2} \mathrm{O} / \mathrm{L}(31)$ and this set will produce an $\mathrm{E}_{\mathrm{L}} /\left(\mathrm{E}_{\mathrm{L}}+\mathrm{E}_{\mathrm{CW}}\right)$ ratio of $8 /(8+16)=0.33$. Interestingly, in this series of patients, we confirmed that the $E_{L} /\left(E_{L}+E_{C W}\right)$ ratio was significantly lower and the chest wall elastance significantly higher in extrapulmonary than in pulmonary ARDS (31). Indeed, the variability of the $E_{L} /\left(E_{L}+E_{C W}\right)$ ratio accounts for the inadequacy of plateau airway pressure as a surrogate of lung stress and explains why, in a fraction of patients, high or low tidal volume produces a similar stress as shown by the remarkable overlap of individual data in Figure 5.

In this study, we found that tidal volume normalized for ideal body weight is a poor surrogate of lung strain. This is due to the high variability of FRC, well known in ALI/ARDS $(32,33)$, in which the relationship between FRC and body weight is lost due to the presence of lung pathology. As a consequence, a $70-\mathrm{kg}$ 
body weight subject, depending on the kind and extent of his or her lung pathology, may have completely different FRC values (and strain for the same applied tidal volume). The control subjects had lower average strain than patients with ALI/ ARDS, but they presented a similar variability of lung strain. This may appear surprising, because in normal, awake, spontaneously breathing subjects, the FRC, height, and IBW are correlated (34), and this should reduce the variability of the lung strain. In fact, in our control subjects, we could not find any correlation between FRC and body weight/height. We have to consider, however, that all our control subjects were studied during anesthesia and paralysis, which, per se, alter the FRC/ body weight relationship due to collapse of the dependent lung regions (35). In our healthiest surgical subgroup, the reduction of FRC compared with the expected FRC (46) (see Table 3) is in the order of $17 \%$, and anesthesia and paralysis fully account for this reduction $(36,37)$. In medical control subjects, however, the FRC reduction of $45 \%$ exceeds the usual effects of anesthesia. These patients, however, were ventilated for a systemic disease (Table 1), and the lung may have not been as healthy as in the surgical subgroup. In summary, between the subgroups, as well as within the subgroups, we found that $\mathrm{VT}_{\mathrm{T}} \mathrm{IBW}$ is a poor surrogate of lung strain. Not surprisingly, although higher $\mathrm{V}_{\mathrm{T}}$ IBW produced, on average, greater lung strain than low $\mathrm{V}_{\mathrm{T}} \mathrm{IBW}$, in individual patients high or low VT IBW could produce the same strain, due to the remarkable data overlap (see Figure 6).

\section{Stress to Strain Relationship in Healthy and ALI/ARDS Lungs}

In this study, we found that the strain to stress relationship was similar throughout the entire population, as shown by specific lung elastance, which remained constant at a value of approximately $13.5 \mathrm{~cm} \mathrm{H}_{2} \mathrm{O}$ throughout the subgroups and did not change with the mechanical ventilator settings. A similar specific lung elastance implies that similar $\Delta$ transpulmonary pressure produces similar fractional changes of FRC either in healthy or in acutely injured lung. Therefore, a $\Delta \mathrm{P}_{\mathrm{L}}$ of approximately $13.5 \mathrm{~cm} \mathrm{H}_{2} \mathrm{O}$ may cause an FRC of $3 \mathrm{~L}$ to inflate up to $6 \mathrm{~L}$ in normal man, and an FRC of $0.5 \mathrm{~L}$ to inflate up to $1 \mathrm{~L}$ in patients with ARDS. These findings strongly support the "baby lung" concept $(38,39)$ : the greater stiffness of ALI/ARDS lung, as observed by the marked reduction of lung compliance, is due to the large decrease in FRC (baby lung) rather than to deteriorated mechanics of the aerated portion. The ALI/ ARDS lung is "small" rather than "stiff." These observations imply that, in ALI/ARDS lungs, at least in the early phase, interstitial lung edema, cellular infiltration, early fibrosis, or surfactant deficit are not so extensive as to alter intrinsic lung mechanics in the lung regions open to ventilation (40), being the specific lung elastance of ALI/ARDS patients similar to that of control subjects.

\section{Recruitment Effect}

Our quantification of strain must be considered an approximation. In theory, the maximal strain naturally applied to the lung (i.e., at total lung capacity) should be around 2-2.5. In fact, the inextensible collagen fiber network comprises a "stop-length" system that is folded at FRC and should be fully unfolded at total lung capacity (8), preventing further lung expansion. When computing strain not taking into account lung recruitment, we observed, in a few patients, unadjusted raw values as high as 3 or 4, which are clearly overestimates (Figure 6). It is likely that in these patients the lung recruitability was remarkable, and the real strain was lower than that assessed by using raw data.

\section{Clinical Implications}

To date, we cannot define a threshold for "harmful" stress and strain. However, due to the similarity of the stress to strain relationship in acutely injured and healthy lungs, it is conceivable that data derived from healthy animals subjected to "lethal" mechanical ventilation may be used as a first attempt to speculate on a possible harmful threshold. In a study on healthy sheep, in which FRC was reported, "lethal mechanical" ventilation, applied for about 12 (41) and 24 (42) hours, corresponded to an average strain of 2.8 and 2.5 , respectively, the range of strain expected with a lung expanded to total lung capacity. Accordingly, we believe that a strain greater than 2 (i.e., corresponding to an end-inspiratory lung volume in the range of total lung capacity) may be lethal for the lung. Because stress and strain are linked by a remarkably constant proportionality factor, the specific lung elastance (i.e., stress approximately $13.5 \mathrm{~cm} \mathrm{H}_{2} \mathrm{O} \times$ strain), in clinical practice, measuring stress as $\Delta \mathrm{P}_{\mathrm{L}}$ or measuring strain as $\Delta \mathrm{V} / \mathrm{FRC}$ is equivalent. If we know, for example, that a harmful threshold of strain is around 2, it follows that the harmful threshold of stress will be approximately $2 \times 13.5 \mathrm{~cm}$ $\mathrm{H}_{2} \mathrm{O}$ (i.e., approximately $27 \mathrm{~cm} \mathrm{H}_{2} \mathrm{O} \Delta \mathrm{P}_{\mathrm{L}}$ ). Therefore, the recommended plateau airway pressure below $30 \mathrm{~cm} \mathrm{H}_{2} \mathrm{O}$ (43) seems reasonable for most of the patients with ALI/ARDS because only few of them may show, at that level of plateau airway pressure, a $\Delta \mathrm{P}_{\mathrm{L}}$ of approximately $27 \mathrm{~cm} \mathrm{H}_{2} \mathrm{O}$. In our practice, we have been measuring stress and strain for almost 2 years in all patients with ALI/ARDS. In a very small fraction of patients whose "baby lung" was extremely small, we recorded strain values higher than 2 even at VT IBW lower than $6 \mathrm{ml} / \mathrm{kg}$. It is likely that, for these patients, "safe" mechanical ventilation does not exist, and for them we consider extracorporeal support (44). On the other hand, measuring stress and strain may rescue some patients condemned to very low $\mathrm{V}_{\mathrm{T}}$ IBW or PEEP, if physicians only looked at airway plateau pressure. We believe that introducing the measurement of stress and strain into clinical practice will allow to better clarify the safe limits of mechanical ventilation.

Conflict of Interest Statement: D.C. does not have a financial relationship with a commercial entity that has an interest in the subject of this manuscript. E.C. does not have a financial relationship with a commercial entity that has an interest in the subject of this manuscript. P. Cadringher received fees from GE Medical Systems Information Technologies, Inc., as a consulting Hospital Biomedical Engineer for the study entitled "Assessment of the Engstrom Carestation's FRC Measurement against Current Practices and Determination of Lung Thresholds" (since 2007). P. Caironi does not have a financial relationship with a commercial entity that has an interest in the subject of this manuscript. F.V. does not have a financial relationship with a commercial entity that has an interest in the subject of this manuscript. F.P. does not have a financial relationship with a commercial entity that has an interest in the subject of this manuscript. F.T. does not have a financial relationship with a commercial entity that has an interest in the subject of this manuscript. P. Cozzi does not have a financial relationship with a commercial entity that has an interest in the subject of this manuscript. M.C. does not have a financial relationship with a commercial entity that has an interest in the subject of this manuscript. A.C. does not have a financial relationship with a commercial entity that has an interest in the subject of this manuscript. J.J.M. does not have a financial relationship with a commercial entity that has an interest in the subject of this manuscript. L.G. reports receiving fees from GE Medical Systems Information Technologies, Inc., as Principal Investigator for the study entitled "Assessment of the Engstrom Carestation's FRC Measurement against Current Practices and Determination of Lung Thresholds" (since 2007).

Acknowledgment: The authors thank Prof. Rolf D. Hubmayr, Section Head, Pulmonary and Critical Care Medicine, Mayo Clinic College of Medicine (Rochester, MN), for his helpful criticism in reviewing the manuscript. They also thank the physicians and nursing staff of the Dipartimento di Anestesia, Rianimazione (Intensiva e Subintensiva) e Terapia del Dolore, Fondazione IRCCS-"Ospedale Maggiore Policlinico Mangiagalli Regina Elena" di Milano for their valuable cooperation.

\section{References}

1. Kumar A, Falke KJ, Geffin B, Aldredge CF, Laver MB, Lowenstein E, Pontoppidan H. Continuous positive-pressure ventilation in acute respiratory failure. N Engl J Med 1970;283:1430-1436.

2. Webb HH, Tierney DF. Experimental pulmonary edema due to intermittent positive pressure ventilation with high inflation pressures: protection by positive end-expiratory pressure. Am Rev Respir Dis 1974;110:556-565. 
3. Dreyfuss D, Soler P, Basset G, Saumon G. High inflation pressure pulmonary edema: respective effects of high airway pressure, high tidal volume, and positive end-expiratory pressure. Am Rev Respir Dis 1988;137:1159-1164.

4. Mead J, Takishima T, Leith D. Stress distribution in lungs: a model of pulmonary elasticity. J Appl Physiol 1970;28:596-608.

5. Haitsma JJ, Lachmann B. Lung protective ventilation in ARDS: the open lung maneuver. Minerva Anestesiol 2006;72:117-132.

6. Tremblay L, Valenza F, Ribeiro SP, Li J, Slutsky AS. Injurious ventilatory strategies increase cytokines and c-fos m-RNA expression in an isolated rat lung model. J Clin Invest 1997;99:944-952.

7. Weibel ER. The pathway for oxygen: structure and function in the mammalian respiratory system. Cambridge, MA: Harvard University Press; 1984.

8. Maksym GN, Bates JH. A distributed nonlinear model of lung tissue elasticity. J Appl Physiol 1997;82:32-41.

9. Maksym GN, Fredberg JJ, Bates JH. Force heterogeneity in a twodimensional network model of lung tissue elasticity. J Appl Physiol 1998:85:1223-1229.

10. Liu M, Tanswell AK, Post M. Mechanical force-induced signal transduction in lung cells. Am J Physiol 1999;277:L667-L683.

11. Vlahakis NE, Schroeder MA, Pagano RE, Hubmayr RD. Deformationinduced lipid trafficking in alveolar epithelial cells. Am J Physiol Lung Cell Mol Physiol 2001;280:L938-L946.

12. Pugin J. Molecular mechanisms of lung cell activation induced by cyclic stretch. Crit Care Med 2003;31:S200-S206.

13. Wilson TA. Solid mechanics. In: American Physiological Society, editor. Handbook of physiology: a critical, comprehensive presentation of physiological knowledge and concepts. Baltimore, MD: Waverly Press; 1986. pp. 35-39.

14. Gattinoni L, Carlesso E, Cadringher P, Valenza F, Vagginelli F, Chiumello D. Physical and biological triggers of ventilator-induced lung injury and its prevention. Eur Respir J Suppl 2003;47:15s-25s.

15. Bernard GR, Artigas A, Brigham KL, Carlet J, Falke K, Hudson L, Lamy M, Legall JR, Morris A, Spragg R. The American-European Consensus Conference on ARDS: definitions, mechanisms, relevant outcomes, and clinical trial coordination. Am J Respir Crit Care Med 1994;149:818-824.

16. Chiumello D, Cressoni M, Racagni M, Landi L, Li BG, Polli F, Carlesso E, Gattinoni L. Effects of thoraco-pelvic supports during prone position in patients with acute lung injury/acute respiratory distress syndrome: a physiological study. Crit Care 2006;10:R87.

17. Aliverti A, Carlesso E, Dellaca R, Pelosi P, Chiumello D, Pedotti A, Gattinoni L. Chest wall mechanics during pressure support ventilation. Crit Care 2006;10:R54.

18. Damia G, Mascheroni D, Croci M, Tarenzi L. Perioperative changes in functional residual capacity in morbidly obese patients. Br J Anaesth 1988;60:574-578.

19. Ranieri VM, Zhang H, Mascia L, Aubin M, Lin CY, Mullen JB, Grasso $\mathrm{S}$, Binnie M, Volgyesi GA, Eng P, et al. Pressure-time curve predicts minimally injurious ventilatory strategy in an isolated rat lung model. Anesthesiology 2000;93:1320-1328.

20. Brander L, Ranieri VM, Slutsky AS. Esophageal and transpulmonary pressure help optimize mechanical ventilation in patients with acute lung injury. Crit Care Med 2006;34:1556-1558.

21. Hager DN, Brower RG. Customizing lung-protective mechanical ventilation strategies. Crit Care Med 2006;34:1554-1555.

22. Pelosi P, D'Andrea L, Vitale G, Pesenti A, Gattinoni L. Vertical gradient of regional lung inflation in adult respiratory distress syndrome. Am J Respir Crit Care Med 1994;149:8-13.

23. Pelosi P, Goldner M, McKibben A, Adams A, Eccher G, Caironi P, Losappio S, Gattinoni L, Marini JJ. Recruitment and derecruitment during acute respiratory failure: an experimental study. Am J Respir Crit Care Med 2001;164:122-130.

24. Cherniack RM, Farhi LE, Armstrong BW, Proctor DF. A comparison of esophageal and intrapleural pressure in man. J Appl Physiol 1955;8: 203-211.

25. Higgs BD, Behrakis PK, Bevan DR, Milic-Emili J. Measurement of pleural pressure with esophageal balloon in anesthetized humans. Anesthesiology 1983;59:340-343.
26. Gillespie DJ, Lai YL, Hyatt RE. Comparison of esophageal and pleural pressures in the anesthetized dog. J Appl Physiol 1973;35:709-713.

27. Polese G, Rossi A, Appendini L, Brandi G, Bates JH, Brandolese R. Partitioning of respiratory mechanics in mechanically ventilated patients. J Appl Physiol 1991;71:2425-2433.

28. Talmor D, Sarge T, O'Donnell CR, Ritz R, Malhotra A, Lisbon A, Loring SH. Esophageal and transpulmonary pressures in acute respiratory failure. Crit Care Med 2006;34:1389-1394.

29. Pelosi P, Cereda M, Foti G, Giacomini M, Pesenti A. Alterations of lung and chest wall mechanics in patients with acute lung injury: effects of positive end-expiratory pressure. Am J Respir Crit Care Med 1995; 152:531-537.

30. Chiumello D, Carlesso E, Aliverti A, Dellaca RL, Pedotti A, Pelosi PP, Gattinoni L. Effects of volume shift on the pressure-volume curve of the respiratory system in ALI/ARDS patients. Minerva Anestesiol 2007;73:109-118.

31. Gattinoni L, Pelosi P, Suter PM, Pedoto A, Vercesi P, Lissoni A. Acute respiratory distress syndrome caused by pulmonary and extrapulmonary disease: different syndromes? Am J Respir Crit Care Med 1998; 158:3-11.

32. MacNaughton PD, Evans TW. Measurement of lung volume and D $\mathrm{L}_{\mathrm{CO}}$ in acute respiratory failure. Am J Respir Crit Care Med 1994;150:770-775.

33. Rylander C, Tylen U, Rossi-Norrlund R, Herrmann P, Quintel M, Bake B. Uneven distribution of ventilation in acute respiratory distress syndrome. Crit Care 2005;9:R165-R171.

34. Stocks J, Quanjer PH. Reference values for residual volume, functional residual capacity and total lung capacity: ATS Workshop on Lung Volume Measurements. Official Statement of the European Respiratory Society. Eur Respir J 1995;8:492-506.

35. Brismar B, Hedenstierna G, Lundquist H, Strandberg A, Svensson L, Tokics L. Pulmonary densities during anesthesia with muscular relaxation-a proposal of atelectasis. Anesthesiology 1985;62:422-428.

36. Hedenstierna G, Strandberg A, Brismar B, Lundquist H, Svensson L, Tokics L. Functional residual capacity, thoracoabdominal dimensions, and central blood volume during general anesthesia with muscle paralysis and mechanical ventilation. Anesthesiology 1985;62:247254.

37. Nunn JF. Elastic forces and lung volumes. In: Nunn JF, editor. Nunn's applied respiratory physiology, 4th ed. Oxford, UK: ButterworthHeinemann; 1993. pp. 36-60.

38. Gattinoni L, Pesenti A, Avalli L, Rossi F, Bombino M. Pressure-volume curve of total respiratory system in acute respiratory failure: computed tomographic scan study. Am Rev Respir Dis 1987;136:730-736.

39. Gattinoni L, Pesenti A. The concept of "baby lung." Intensive Care Med 2005:31:776-784.

40. Gattinoni L, D'Andrea L, Pelosi P, Vitale G, Pesenti A, Fumagalli R. Regional effects and mechanism of positive end-expiratory pressure in early adult respiratory distress syndrome. JAMA 1993;269:21222127.

41. Mandava S, Kolobow T, Vitale G, Foti G, Aprigliano M, Jones M, Muller E. Lethal systemic capillary leak syndrome associated with severe ventilator-induced lung injury: an experimental study. Crit Care Med 2003;31:885-892.

42. Kolobow T, Moretti MP, Fumagalli R, Mascheroni D, Prato P, Chen V, Joris M. Severe impairment in lung function induced by high peak airway pressure during mechanical ventilation: an experimental study. Am Rev Respir Dis 1987;135:312-315.

43. The Acute Respiratory Distress Syndrome Network. Ventilation with lower tidal volumes as compared with traditional tidal volumes for acute lung injury and the acute respiratory distress syndrome. $N$ Engl $J$ Med 2000;342:1301-1308.

44. Kopp R, Dembinski R, Kuhlen R. Role of extracorporeal lung assist in the treatment of acute respiratory failure. Minerva Anestesiol 2006;72: 587-595.

45. Crotti S, Mascheroni D, Caironi P, Pelosi P, Ronzoni G, Mondino M, Marini JJ, Gattinoni L. Recruitment and derecruitment during acute respiratory failure: a clinical study. Am J Respir Crit Care Med 2001; 164:131-140.

46. Ibanez J, Raurich JM. Normal values of functional residual capacity in the sitting and supine positions. Intensive Care Med 1982;8:173-177. 